\title{
Anthropometric and Body Composition Measurements Related to Osteoporosis in Geriatric Population
}

\section{Geriatrik Popülasyonda Osteoporoz ile İlişkili Antropometrik ve Vücut Kompozisyonu Ölçümleri}

\author{
(D) Sadiye MURAT1, (D) Bilinc DOGRUOZ KARATEKIN1, (1) Filiz DEMIRDAG², (D) Esma Nur KOLBASI3
}

IIstanbul Medeniyet University Goztepe Prof. Dr. Suleyman Yalcin City Hospital, Department of Physical Medicine and Rehabilitation, Istanbul, Turkey ${ }^{2}$ Goztepe Prof. Dr. Suleyman Yalcin City Hospital, Clinic of Internal Medicine, Division of Geriatrics, Istanbul, Turkey

3Istanbul Medeniyet University Faculty of Health Sciences, Physiotherapy and Rehabilitation, Istanbul, Turkey

\begin{abstract}
Objective: This study aimed to evaluate different anthropometric and body composition measurements, including weight, body mass index (BMI), body fat percentage (fat\%), skeletal muscle index (SMI), a body shape index (ABSI), waist circumference (WC), and hip circumference (HC), in relation to bone mineral density.

Methods: This is a cross-sectional study of a total of 482 patients who consulted the geriatric outpatient clinic between 2018 and 2019. Patients were evaluated with dual-energy X-ray absorptiometry. Anthropometric measurements (HC, WC, weight, BMI, and ABSI), as well as body composition analysis (fat\% and SMI) by bioimpedance analysis system, were performed. The patients were evaluated with the rapid Assessment of Physical Activity Index in terms of aerobic exercise habits.

Results: There was a significant correlation between lumbar spine (LS) T-score and SMI ( $r=0.36, p=0.000)$ and between LS T-score and weight $(r=0.21, p=0.000)$, BMI $(r=0.10, p=0.045)$ and WC $(r=0.15, p=0.001)$. There was a statistically significant correlation between femur neck (FN) $\mathrm{T}$-score and fat $\%(r=0.15, p=0.001)$, SMI $(r=0.15, p=0.010)$, weight $(r=0.22, p=0.000)$, BMI $(r=0.20, p=0.000)$, WC $(r=0.14, p=0.003)$, and HC $(r=0.17$, $\mathrm{p}=0.001)$. There was no statistically significant correlation between physical activity and LS T-score $(\mathrm{n}=353$, $\mathrm{r}=0.08, \mathrm{p}=0.16)$ and FN T-score $(\mathrm{n}=360, \mathrm{r}=0.03, \mathrm{p}=0.53)$. In multiple regression analysis, SMI contributes most in predicting FN and LS T-scores.

Conclusions: Anthropometric measurements should be carefully selected in the geriatric population. Among the measurements, the strongest relationship was found between LS T-score and SMI.

Keywords: Anthropometrics, fat percentage, osteoporosis, skeletal muscle index
\end{abstract}

Received: 17 August 2021

Accepted: 16 November 2021

Online First: 08 December 2021

Corresponding Author

B. Dogruoz Karatekin

Istanbul Medeniyet University;

Goztepe Prof. Dr. Suleyman Yalcin City Hospital, Department of Physical Medicine and Rehabilitation, Istanbul,

Turkey

bilincdogruoz@hotmail.com ORCID: 0000-0002-0568-9498

\section{Öz}

Amaç: Bu çalışmanın amacı, farklı antropometrik ve vücut kompozisyonu ölçümlerini [ağırlık, vücut kitle indeksi (VKİ), vücut yağ yüzdesi (\%yağ), iskelet kası indeksi (iKí), vücut şekil indeksi (VŞì), bel çevresi (BÇ) ve kalça çevresi (KÇ)] ölçmek ve bu ölçümlerin kemik mineral yoğunluğu ile ilişkisini araştırmaktır.

Yöntemler: Bu çalışma, 2018-2019 yılları arasında geriatri polikliniğine başvuran 482 hastanın dahil edildiği kesitsel bir çalışmadır. Hastaların kemik mineral yoğunlukları dual-enerji X-ışını absorbsiyometri ile değerlendirildi. Biyoimpedans analiz sistemi ile antropometrik değerlendirmeler ve ölçümler (KÇ, BÇ, ağırlık, VKï, VŞi) ve vücut kompozisyon analizi (\%yağ, IKi) yapıldı. Hastalar aerobik egzersiz alışkanlıkları açısından Fiziksel Etkinliklerin Hızlı Değerlendirilme Ölçeği aerobik bölümü ile değerlendirildi.

Bulgular: Lomber omurga (LO) T-skoru ile İKi ( $\mathrm{r}=0,36, \mathrm{p}=0,000)$ arasında ve lomber T-skoru ile ağırlık ( $\mathrm{r}=0,21$, $\mathrm{p}=0,000)$, VKi $(r=0,10, p=0,045)$ ve $B C ̧(r=0,15, p=0,001)$ arasında istatistiksel olarak anlamlı ilişki vardı. Femur

Cite as: Murat S, Dogruoz Karatekin B, Demirdag F, Kolbasi EN. Anthropometric and Body Composition Measurements Related to Osteoporosis in Geriatric Population. Medeni Med J 2021;36:294-301 
boynu (FB) T-skoru ile \%yağ ( $r=0,15, p=0,001)$, íi ( $r=0,15, p=0,010)$, ağırlık ( $r=0,22, p=0,000)$, VKi $(r=0,20, p=0,000), B C ̧ \quad(r=0,14, p=0,003)$ ve KÇ $(r=0,17, p=0,001)$ arasında istatistiksel olarak anlamlı korelasyon vardı. Fiziksel aktivite ile LO T-skoru $(n=353, r=0,08, p=0,16)$ ve FB T-skoru $(n=360, r=0,03, p=0,53)$ arasında istatistiksel olarak anlamlı bir ilişki yoktu. Çoklu regresyon analizinde İKİ, FB ve LO T-skorlarını tahmin etmeye en çok katkıda bulunan değişken olarak saptandl.

Sonuçlar: Geriatrik popülasyonda antropometrik ölçümler dikkatli seçilmelidir. Ölçümler arasında en güçlü ilişki LO T-skoru ve İK̇ arasında saptanmıştır. Anahtar kelimeler: Antropometrik, yağ yüzdesi, osteoporoz, iskelet kası indeksi

\section{INTRODUCTION}

Osteoporosis is a systemic skeletal disease characterized by low bone mineral density (BMD) and impaired bone microarchitecture that can lead to increased fracture risk'. In contrast with the general belief that obesity reduces the risk of fractures, recent studies have shown that a significant proportion of postmenopausal women with low-energy fractures are obese ${ }^{2}$.

According to the results of Turkey Diabetes, Obesity and Hypertension Epidemiology Research I and II, which was obtained with intervals of twelve years, the prevalence of obesity increased by $40 \%$. The rate of obesity is reported to be $44 \%$ in women and $27 \%$ in men 3 . Considering obesity as a protective factor in osteoporosis patients may delay the fight against an existing health problem.

The relationship between metabolic syndrome and osteoporosis has been the focus of many studies in recent years. Von Muhlen et al. ${ }^{4}$ reported that metabolic syndrome is associated with low BMD values and an increased frequency of non-vertebral fractures. Also, it has been reported that high abdominal fat mass is associated with a decreased risk of fracture in elderly women ${ }^{5}$.

Anthropometric measures are simple, inexpensive, and practical tools for population screening and early detection of several diseases ${ }^{6}$. Body mass index (BMI) is the most commonly used anthropometric measure that has been shown to be associated with several diseases, as well as mortality 7.8 . Recently, a new anthropometric measurement, known as a body shape index (ABSI), was developed to estimate the risks of diseases that cannot be predicted by $\mathrm{BMI}^{9}$.

Many anthropometric measurements that are associated with osteoporosis have been proposed. There is no definite opinion on which anthropometric measurement has a higher association with osteoporosis $^{10-12}$.

In literature, both positive $e^{13.14}$ and negative $e^{15,16}$ correlations between anthropometric indices and BMD have been reported. Among these anthropometric indices, the waist circumference (WC) or waist-to-hip ratio has been reported to have a stronger association with BMD compared to $\mathrm{BMI}^{16,17}$. In addition, some studies have reported that fat mass can adversely affect skeletal health compared to lean mass ${ }^{18.19}$. Given the conflicting results in literature, there is a need to thoroughly investigate the association between anthropometric measurements and osteoporosis.

In this regard, we took different anthropometric and body composition measurements, such as body weight, BMI, body fat percentage (fat\%), skeletal muscle index (SMI), ABSI, WC, and hip circumference (HC), in order to investigate the relationship with to lumbar spine (LS) and femur neck (FN) T-scores.

\section{MATERIALS and METHODS}

Patients who consulted to the geriatric outpatient clinic between 2018 and 2019 were included in the study. The inclusion criteria were: patients aged $\geq 65$ years and diagnosed with osteoporosis according to the definition of World Health Organization ${ }^{20}$. The exclusion criteria were: vertebral fracture due to known accidental traumas, history of drug therapy in the past year (bisphosphonate, estrogen replacement therapy, and glucocorticoids), history of comorbidities, such as malignancy, radiotherapy or chemotherapy, renal failure, hyperthyroidism, primer hyperparathyroidism, and rheumatic disease or adrenal diseases.

Initially, a demographic form, including age, sex, and comorbidities, was filled by the participants. The BMI, which is a ratio of weight and height squared $\left(\mathrm{kg} / \mathrm{m}^{2}\right)$, was calculated. The patient's WC and HC were also measured in centimeter and their fat $\%$ and skeletal muscle mass (SMM) were calculated by bioimpedance analysis (BIA) (Tanita TBF 300; Tanita Corp., Tokyo, Japan). SMI was calculated from the BIA-based SMM with the formula $\mathrm{SMM} /$ height $\left(\mathrm{m}^{2}\right)^{21}$. ABSI was measured with the formula WC $(\mathrm{m}) /\left[\text { Weight }(\mathrm{kg})^{2 / 3 \times} \times \text { Height }(\mathrm{m})^{5 / 6}\right]^{9}$.

Osteoporosis was evaluated by dual-energy X-ray absorptiometry (DXA). According to the T-scores 
calculated from FN and LS, the participants were divided into three groups according to FN score as follows: normal: T-score >-1, osteopenia: T-score is between -1 and -2.5 , and osteoporosis: T-score $<-2.5{ }^{20}$. Also, vitamin D, calcium, phosphorus, parathyroid hormone (PTH), and alkaline phosphatase (ALP) levels were recorded.

Physical activity levels of the patients were evaluated with the rapid assessment of physical activity (RAPA) aerobic assessment, which is a valid and reliable tool used in the elderly ${ }^{22}$. Accordingly, patients were divided into five groups as follows: $1=$ sedentary, $2=$ underactive, $3=$ regular underactive (light activities), and $4=$ regular underactive, and $5=$ regular active).

The study protocol was approved by the Clinical Research Ethics Committee of the Istanbul Medeniyet University Goztepe Training and Research Hospital (decision no: 2018/0478, date: 12.12.2018) and all participants gave written informed consent. This study is registered to clinicaltrials.gov p(NCT04255173).

\section{Statistical Analysis}

All statistical analyses were performed with SPSS Statistics for Windows, version 25.0 (IBM corps., Chicago, IL., USA). Pearson correlation ( $r$ ) and Spearman correlation (rho) were used to determine the relationship between variables. Multiple regression was used to determine the best linear combination of variables. ANOVA was used to examine the differences in variables between more than two groups. $\mathrm{P}$ values less than 0.05 were considered statistically significant.

A post hoc power analysis was done using $G^{*}$ Power 3 (Faul et al.') to 1) determine the relationship between LS T-score and FN T-score with other variables (fat\%, SMI, BMI, WC, HC, and weight) using a one-tailed test, 2) conduct a multiple regression analysis of six predictor variables, 3) determine the relationship between RAPA aerobic physical activity and four variables (fat \%, SMI, $\mathrm{BMI}$, and $\mathrm{HC}$ ) using a one-tailed test, and 4) determine the relationship between RAPA aerobic physical activity and a laboratory test $\mathrm{P}$ using a one-tailed test.

\section{RESULTS}

During data collection, a total of 571 participants were included in the study. Individuals who did not meet the inclusion criteria and had missing DXA values were excluded. After the exclusion of non-eligible individuals, a total of 482 patients (mean age $=74.27 \pm 7.40$ years), which comprise 331 females (68.7\%) and 151 males (31.3\%), participated in the study. Among, 482 patients, 134 patients were diagnosed of osteoporosis $(30.39 \%)$ and 254 patients were diagnosed of osteopenia (57.60\%). According to RAPA aerobic index, the 482 patients were classified as follows: sedentary patients: 16 (3.3\%), underactive patients: 12 (2.5\%), regular underactive (light activities): 136 (28.2\%), regular underactive: 187 (38.8\%), and regular active: $131(27.2 \%)$. The other characteristics of the patients are presented in Table 1.

The relationship between of LS and FN T-scores with the anthropometric measurements was investigated using Pearson correlation coefficient ( $r$ ). Table 2 shows the results of Pearson correlation ( $r$ ) analysis. There was a weak positive relationship between LS T-score and SMI $(\mathrm{r}=0.36, \mathrm{p}=0.000)$ and between LS T-score and weight $(\mathrm{r}=0.21, \mathrm{p}=0.000)$, BMI $(\mathrm{r}=0.10, \mathrm{p}=0.045)$, and WC $(r=0.15, p=0.001)$. There was a weak relationship between FN T-score and fat $\%(r=0.15, p=0.001)$, SMI $(r=0.15, p=0.010)$, weight $(r=0.22, p=0.000)$, BMI $(r=0.20, p=0.000)$, WC $(\mathrm{r}=0.14, \mathrm{p}=0.003)$, and $\mathrm{HC}(\mathrm{r}=0.17, \mathrm{p}=0.001)$.

The above correlation results indicate that the variables fat $\%$, SMI, BMI, WC, HC, and weight are associated with LS and FN T-score. To ascertain the highest possible multiple correlations of these variables with LS and FN T-score and to elaborate these relationships, multiple regression analysis was performed.

A post hoc power analysis was conducted using $\mathrm{G}^{*}$ Power $3^{1}$ to determine the relationship between LS T-score and FN T-score with other variables (fat \%, SMI, $\mathrm{BMI}, \mathrm{WC}, \mathrm{HC}$, and weight) using a one-tailed test, with a total sample of 482 participants and an alpha of 0.05 . Results show that the achieved power was more than 0.99 for the LS T-score and SMI and that it was 0.70 for the other significant relationships.

Multiple regression was conducted to determine the best linear combination of fat\%, BMI, WC, HC, weight, and SMI for predicting LS T-scores. This combination of variables significantly predicted LST-score $(\mathrm{F}[6,352]=12.20$, $\mathrm{p}<0.001$ ), with four variables (fat\%, WC, weight, and SMI) significantly contributing to the prediction. The adjusted $\mathrm{R}$ squared value was 0.16 , which indicates that $16 \%$ of the variance in the LS T-score was explained by the model. According to Cohen ${ }^{2}$ this is a small effect. The beta weights, presented in Table 3 , suggest that SMI contributes most to the prediction of LS T-score and that WC, weight, and fat $\%$ also contribute to the prediction. 


\begin{tabular}{|c|c|c|c|c|}
\hline Variables & Min & Max & Mean & SD \\
\hline Age & 65.00 & 99.00 & 74.27 & 6.73 \\
\hline LS T-score & -5.10 & 5.20 & -1.20 & 1.62 \\
\hline FN T-score & -4.00 & 4.60 & -1.58 & 1.05 \\
\hline Fat $\%$ & 9.90 & 50.90 & 33.18 & 8.65 \\
\hline ABSI & 0.33 & 2.89 & 0.86 & 0.13 \\
\hline SMI & 0.87 & 10.10 & 7.32 & 0.85 \\
\hline Weight (kg) & 60.00 & 120.00 & 71.54 & 13.87 \\
\hline BMI $\left(\mathrm{kg} / \mathrm{m}^{2}\right)$ & 16.80 & 78.00 & 28.73 & 5.56 \\
\hline Waist circumference $(\mathrm{cm})$ & 40.80 & 133.00 & 99.25 & 12.46 \\
\hline Hip circumference $(\mathrm{cm})$ & 13.00 & 164.00 & 106.53 & 10.78 \\
\hline Vitamin D (ng/mL) & 2.40 & 115.00 & 25.81 & 14.85 \\
\hline PTH $(\mathrm{pg} / \mathrm{mL})$ & 47.6 & 210.00 & 69.50 & 36.17 \\
\hline Calcium (mg/dL) & 7.60 & 11.30 & 9.61 & 0.63 \\
\hline $\mathrm{P}(\mathrm{mg} / \mathrm{dL})$ & 1.80 & 7.30 & 3.51 & 0.55 \\
\hline \multirow[t]{2}{*}{ ALP (IU/L) } & 15.00 & 437.00 & 74.54 & 33.13 \\
\hline & \multicolumn{2}{|l|}{$\mathbf{n}$} & \multicolumn{2}{|l|}{$\%$} \\
\hline \multicolumn{5}{|l|}{ Gender } \\
\hline Female & \multicolumn{2}{|l|}{331} & \multicolumn{2}{|l|}{68.7} \\
\hline Male & \multicolumn{2}{|l|}{151} & \multicolumn{2}{|l|}{31.3} \\
\hline Osteoporosis & \multicolumn{2}{|l|}{134} & \multicolumn{2}{|l|}{30.39} \\
\hline Osteopenia & \multicolumn{2}{|l|}{254} & \multicolumn{2}{|l|}{57.60} \\
\hline \multicolumn{5}{|l|}{ RAPA aerobic index } \\
\hline Sedantery & \multicolumn{2}{|l|}{16} & \multicolumn{2}{|l|}{3.3} \\
\hline Underactive & \multicolumn{2}{|l|}{12} & \multicolumn{2}{|l|}{2.5} \\
\hline $\begin{array}{l}\text { Regular underactive-light } \\
\text { activities }\end{array}$ & \multicolumn{2}{|l|}{136} & \multicolumn{2}{|l|}{28.2} \\
\hline Regular underactive & \multicolumn{2}{|l|}{187} & \multicolumn{2}{|l|}{38.8} \\
\hline Regular active & \multicolumn{2}{|l|}{131} & \multicolumn{2}{|l|}{27.2} \\
\hline
\end{tabular}

Table 2. Pearson correlation (r) analysis of variables with LS and FN T-scores.

\begin{tabular}{|l|l|l|l|l|}
\hline & \multicolumn{2}{|c|}{ L1-4 } & \multicolumn{2}{c|}{ Femur neck } \\
\hline Variables & r & P & r & P \\
\hline Fat\% & -0.01 & 0.81 & $0.15^{\mathrm{b}}$ & $<0.01$ \\
\hline SMI & $0.36^{\mathrm{c}}$ & $<0.001$ & $0.15^{\mathrm{b}}$ & $<0.01$ \\
\hline ABSI & 0.05 & 0.33 & 0.003 & 0.95 \\
\hline Weight & $0.21^{\mathrm{c}}$ & $<0.001$ & $0.22^{\mathrm{c}}$ & $<0.001$ \\
\hline BMI & $0.10^{\mathrm{a}}$ & $<0.05$ & $0.20^{\mathrm{c}}$ & $<0.001$ \\
\hline Waist circumference & $0.15^{\mathrm{b}}$ & $<0.01$ & $0.15^{\mathrm{b}}$ & $<0.01$ \\
\hline Hip circumference & 0.02 & 0.67 & $0.17^{\mathrm{c}}$ & $<0.001$ \\
\hline
\end{tabular}

${ }^{a}$ Statistically significant relationship between variables at level of $\mathrm{p}<0.05$, ${ }^{\mathrm{b}} \mathrm{p}<0.01$, ${ }^{\mathrm{c}} \mathrm{p}<0.001$. LS: Lumbar spine, FN: Femur neck, ABSI: A body shape index, SMI: Skeletal muscle index, BMI: Body mass index, Fat\%: Body fat percentage 
A post hoc power analysis was conducted using $\mathrm{G}^{*}$ Power $3^{1}$ to determine the multiple regression analysis of six predictor variables with 0.16 adjusted $\mathrm{R}$ square, a total sample size of 482 , and an alpha of 0.05 . The results show that the achieved power was 0.99 .

Multiple regression was conducted to determine the best linear combination of fat\%, BMI, WC, and HC, weight, and SMI for predicting FN T-scores (Table 3). This combination of variables significantly predicted FN T-score ( $F[6,357]=5.46, p<0.001)$, with two variables (fat $\%$ and SMI) significantly contributing to the prediction. The adjusted $\mathrm{R}$ squared value was 0.07 , which indicates that $7 \%$ of the variance in FN T-score was explained by the model. According to Cohen ${ }^{2}$ this is also a small effect. The beta weights, presented in Table 3, suggest that SMI contributes most to the prediction of FN T-score and that fat $\%$ also contributes to this prediction. A post hoc power analysis was conducted using $G^{*}$ Power 3 (1) to determine the multiple regression analysis of six predictor variables with 0.07 adjusted $R$ square, a total sample size of 482 , and an alpha of 0.05 . The results show that the achieved power was 0.99 .

The relationship between aerobic physical activity (as measured by RAPA index) and the variables (fat $\%$, SMI, ABSI, weight, BMI, WC, and $\mathrm{HC}$ ) was investigated using
Spearman's correlation coefficient (rho). Table 4 shows the results of Spearman's correlation (rho) analysis. There were weak negative correlations between physical activity and fat $\%(r=-0.23, p=0.000)$, BMI $(r=-0.12, p=0.031)$, and $\mathrm{HC}(\mathrm{r}=-0.10, \mathrm{p}=0.050)$ and a weak positive relationship between physical activity and appendicular muscle mass $(\mathrm{r}=0.11, \mathrm{p}=0.030)$.

A post hoc power analysis was conducted using $\mathrm{G}^{*}$ Power $3^{1}$ to determine the relationship between RAPA aerobic physical activity with four variables (fat $\%$, SMI, $\mathrm{BMI}$, and $\mathrm{HC}$ ) using a one-tailed test, with a total sample of 482 participants and an alpha of 0.05. Results show that the achieved power was more than 0.99 for fat $\%$, 0.78 for SMI, 0.84 for BMI, and 0.71 for HC.

The relationship between aerobic physical activity (as measured by RAPA index) and laboratory assays (vitamin D, PTH, calcium, phosphorus, and ALP) was investigated by Spearman's correlation analysis. There was a weak negative relationship between physical activity and $P$ $(\mathrm{r}=-0.12)$. A post hoc power analysis was conducted using $\mathrm{G}^{*}$ Power 3 (Faul et al.') to determine the relationship between RAPA aerobic physical activity with phosphorus using a one-tailed test, with a total sample of 482 participants and an alpha of 0.05 . The achieved power was 0.84 .

\section{Table 3. Multiple regression analysis for LS T-score.}

\begin{tabular}{|c|c|c|c|c|c|c|}
\hline Variables & B & SEB & $\boldsymbol{B}$ & $\mathbf{p}$ & $95 \%$ CI for B & VIF \\
\hline Fat $\%$ & 0.04 & 0.02 & $0.23^{b}$ & $<0.01$ & $0.01-0.07$ & 2.65 \\
\hline BMI & 0.00 & 0.03 & -0.01 & 0.89 & $-0.06-0.05$ & 3.49 \\
\hline SMI & 0.77 & 0.12 & $0.40^{c}$ & $<0.001$ & $0.54-1.00$ & 1.64 \\
\hline Waist & 0.00 & 0.01 & -0.03 & 0.71 & $-0.02-0.02$ & 2.71 \\
\hline Hip & -0.03 & 0.01 & $-0.21^{b}$ & $<0.01$ & $-0.06-(-0.01)$ & 2.62 \\
\hline Weight & 0.02 & 0.01 & $0.19^{a}$ & $<0.05$ & $0.00-0.04$ & 3.59 \\
\hline
\end{tabular}

Table 4. Multiple regression analysis for FN T-score.

\begin{tabular}{|l|l|l|l|l|l|l|}
\hline Variables & B & SEB & B & P & 95\% CI for B & VIF \\
\hline Fat\% & 0.02 & 0.01 & $0.20^{\text {a }}$ & $<0.05$ & $0.01-0.04$ & 2.65 \\
\hline BMI & 0.01 & 0.02 & 0.06 & 0.50 & $-0.02-0.05$ & 3.49 \\
\hline SMI & 0.25 & 0.08 & $0.21^{\text {b }}$ & $<0.01$ & $0.10-0.41$ & 1.64 \\
\hline Waist & -0.01 & 0.01 & -0.10 & 0.15 & $-0.02-0.00$ & 2.71 \\
\hline Hip & 0.00 & 0.01 & -0.02 & 0.76 & $-0.02-0.01$ & 2.2 \\
\hline Weight & 0.01 & 0.01 & 0.15 & 0.12 & $0.00-0.03$ & 3.59 \\
\hline
\end{tabular}

aStatistically significant relationship between variables at level of $\mathrm{p}<0.05,{ }^{\mathrm{b}} \mathrm{p}<0.01$, BMI: Body mass index, SMI: Skeletal muscle index, Fat\%: Body fat percentage, FN: Femur neck, Cl: Confidence interval 
According to Spearman's correlation analysis results, there was no relationship between physical activity and LS T-score $(n=353, r=0.08, p=0.16)$ and FN T-score $(n=360$, $r=0.03, p=0.53$ ) (Table 5). In order to investigate the impact of physical activity on LS and FN T-score variables, ANOVA was performed conducted. The results show that there was no significant difference in LS T-score $(\mathrm{F}[2$, 350] $=0.77, \mathrm{p}=0.47)$ and FN T-score $(\mathrm{F}[2,357]=0.52, \mathrm{p}=0.59)$ between the physical activity groups.

\section{DISCUSSION}

Anthropometric measurements are often preferred because they are cost-effective and can be applied quickly and easily in clinics. Herein, we investigated the relationship between osteoporosis and various anthropometric and body composition measurements (BMI, ABSI, fat\%, SMI, WC, and HC). Among these variables, all measurements, except ABSI, were correlated with LS and FN T-scores.

Previously, obesity was thought to protect against osteoporosis $^{23}$. However, it was recently shown that high fat $\%$ adversely affects the bone health ${ }^{24}$. Although it was not statistically significant, the increase in fat $\%$ was found to be correlated with a decrease in LS T-score and a high fat\% significantly contributes to the DXA scores in the regression analysis. While the cortical bone mainly assumes a mechanical and protective function, the trabecular bone is responsible for metabolic function. Osteoporosis is more common in areas rich in trabecular bone, such as vertebrae ${ }^{25}$. Therefore, changes in body composition may mostly affect the vertebrae. Although the risk of vertebral osteoporosis increases as the fat $\%$ increases, degenerative changes may also increase with age, thereby making accurate assessment difficult.
Although the index most commonly used in obesity screening is BMI, a new obesity index, ABSI, has been developed, considering that $\mathrm{BMI}$ does not distinguish between muscle and fat mass. ABSI has been shown by several studies to be a predictor of several diseases and mortality $9,26,27$. To the best of our knowledge, there is no study investigating the relationship between ABSI and osteoporosis in literature. The ABSI score is an obesity scale based on WC. However, in our study, although BMI and $\mathrm{WC}$ alone were correlated with BMD, ABSI was not correlated BMD. Also, in a recently published review, $\mathrm{ABSI}$ was shown to be outperformed by BMI and WC in predicting all-cause mortality but underperformed in predicting chronic diseases, such as osteoporosis ${ }^{28}$.

Fat $\%$ and SMI were calculated by BIA. The calculation based on BIA has been shown to correlate with the calculation with DXA ${ }^{29}$. In this study, SMI has the strongest relationship with LS and FN T-scores. Moreover, SMI and osteoporosis have been associated in a recent study $^{30}$. SMI is also used in the diagnosis of sarcopenia. BIA measurements in the geriatric population can be an easy and practical way of screening patients at risk of osteoporosis and sarcopenia.

The positive effects of aerobic physical activity on bone health have been shown in many studies ${ }^{31-33}$. In our study, aerobic physical activity was not directly related to the T-scores, which may be due to the low number of sedentary and underactive patients. However, aerobic physical activity was associated with fat $\%$, SMI, BMI, and HC. In addition, fat\%, SMI, BMI, HC, and WC were associated with both LS and FN T-scores. Therefore, we can conclude that aerobic physical activity is indirectly related to the severity of osteoporosis.

\begin{tabular}{|l|l|l|}
\hline \multicolumn{2}{|c|}{ Table 5. Spearman's correlation (rho) analysis of variables with RAPA aerobic physical activity. } \\
\hline & \multicolumn{2}{|c|}{ RAPA aerobic physical activity } \\
\hline Variables & rho & P \\
\hline Fat\% & $-0.23^{\mathrm{c}}$ & $<0.001$ \\
\hline SMI & $0.11^{\mathrm{a}}$ & $<0.05$ \\
\hline ABSI & -0.01 & 0.79 \\
\hline Weight & 0.06 & 0.21 \\
\hline BMI & $-0.12^{\mathrm{a}}$ & $<0.05$ \\
\hline Waist circumference & -0.08 & 0.06 \\
\hline Hip circumference & $-0.10^{\mathrm{a}}$ & $<0.05$ \\
\hline $\begin{array}{l}\text { aStatistically significant relationship between variables at level of } p<0.05,{ }^{b} p<0.01,{ }^{c} p<0.001 . \text { ABSI: A body shape index, SMI: Skeletal muscle index, BMI: Body } \\
\text { mass index, Fat\%: Body fat percentage, RAPA: Rapid assessment of physical activity }\end{array}$ \\
\hline
\end{tabular}


The limitations of the study were the determination of the severity of osteoporosis only according to the T-score, absence of a radiographic evaluation, and possible wrong lumbar DXA results due to degenerative changes.

\section{CONCLUSIONS}

The relationship between $\mathrm{ABSI}$ and osteoporosis severity has not been demonstrated. Among the anthropometric and body composition measurements, BMI, WC, HC, fat \%, and SMI were found to be associated with BMD, with the strongest relationship found between SMI and BMD.

\section{Ethics}

Ethics Committee Approval: The study protocol was approved by the Clinical Research Ethics Committee of the Istanbul Medeniyet University Goztepe Training and Research Hospital (decision no: 2018/0478, date: 12.12.2018)

Informed Consent: All participants gave written informed consent.

Peer-review: Externally and internally peer-reviewed.

\section{Author Contributions}

Concept: S.M., B.D.K., F.D., E.N.K., Design: S.M., B.D.K., F.D., E.N.K., Data Collection and/or Processing: S.M., B.D.K., F.D., E.N.K., Analysis and/or Interpretation: S.M., B.D.K., F.D., E.N.K., Critical Revision: S.M., B.D.K., F.D., E.N.K., Writing: B.D.K.

Conflict of Interest: The authors have no conflict of interest to declare.

Financial Disclosure: The authors declared that this study has received no financial support.

\section{REFERENCES}

1. Faul F, Erdfelder E, Lang AG, Buchner A. G*Power 3: a flexible statistical power analysis program for the social, behavioral, and biomedical sciences. Behav Res Methods. 2007;39:175-91.

2. Cohen J. Statistical power analysis for the behavioral sciences. 2nd ed. Hillsdale, N.J.: L. Erlbaum Associates; 1988.

3. Satman I, Omer B, Tutuncu Y, et al. Twelve-year trends in the prevalence and risk factors of diabetes and prediabetes in Turkish adults. Eur J Epidemiol. 2013;28:169-80.

4. von Muhlen D, Safii S, Jassal SK, Svartberg J, Barrett-Connor E. Associations between the metabolic syndrome and bone health in older men and women: the Rancho Bernardo Study. Osteoporos Int. 2007;18:1337-44.

5. Yang S, Nguyen ND, Center JR, Eisman JA, Nguyen TV. Association between abdominal obesity and fracture risk: a prospective study. J Clin Endocrinol Metab. 2013;98:2478-83.
6. Physical status: the use and interpretation of anthropometry: Report of a WHO Expert Committee. Technical Report Series 1995;No:854.

7. Flegal KM, Kit BK, Orpana H, Graubard BI. Association of all-cause mortality with overweight and obesity using standard body mass index categories: a systematic review and meta-analysis. JAMA. 2013;309:71-82

8. Sharma A, Lavie CJ, Borer JS, et al. Meta-analysis of the relation of body mass index to all-cause and cardiovascular mortality and hospitalization in patients with chronic heart failure. Am J Cardiol. 2015;115:1428-34.

9. Krakauer NY, Krakauer JC. A new body shape index predicts mortality hazard independently of body mass index. PLoS One. 2012;7:e39504. doi: 10.1371/journal.pone.0039504.

10. Neri SGR, Gadelha AB, de David AC, et al. The association between body adiposity measures, postural balance, fear of falling, and fall risk in older community-dwelling women. J Geriatr Phys Ther. 2019;42:E94-100. doi: 10.1519/JPT.0000000000000165.

11. Shin H, Liu PY, Panton LB, Ilich JZ. Physical performance in relation to body composition and bone mineral density in healthy, overweight. and obese postmenopausal women. J Geriatr Phys Ther. 2014;37:7-16.

12. Aghaei Meybodi H, Hemmat-Abadi M, Heshmat R, et al. Association between anthropometric measures and bone mineral density: population-based study. Iran J Public Health. 2011;40:18-24.

13. Salamat MR, Salamat AH, Abedi I, Janghorbani M. Relationship between weight, body mass index, and bone mineral density in men referred for dual-energy x-ray absorptiometry scan in Isfahan, Iran. J Osteoporos. 2013;2013:205963. doi: 10.1155/2013/205963.

14. Hoxha R, Islami H, Qorraj-Bytyqi H, Thaçi S, Bahtiri E. Relationship of weight and body mass index with bone mineral density in adult men from kosovo. Mater Sociomed. 2014;26:306-8.

15. Zhang P, Peterson M, Su GL, Wang SC. Visceral adiposity is negatively associated with bone density and muscle attenuation. Am J Clin Nutr. 2015;101:337-43.

16. Cherif R, Mahjoub F, Sahli H, et al. Positive association of obesity and insulin resistance with bone mineral density in tunisian postmenopausal women. J Clin Densitom. 2018;21:163-71.

17. Alissa EM, Alnahdi WA, Alama N, Ferns GA. Relationship between nutritional profile, measures of adiposity, and bone mineral density in postmenopausal Saudi women. J Am Coll Nutr. 2014;33:206-14.

18. Leslie WD. Orwoll ES, Nielson CM, et al. Estimated lean mass and fat mass differentially affect femoral bone density and strength index but are not FRAX independent risk factors for fracture. J Bone Miner Res. 2014;29:2511-9.

19. Kim HY, Jung HW, Hong $\mathrm{H}$, et al. The role of overweight and obesity on bone health in korean adolescents with a focus on lean and fat mass. J Korean Med Sci. 2017:32:1633-41.

20. Kanis JA, McCloskey EV, Johansson H, Oden A, Melton LJ, Khaltaev $\mathrm{N}$. A reference standard for the description of osteoporosis. Bone. 2008;42:467-75.

21. Newman AB, Kupelian V, Visser M, et al. Sarcopenia: alternative definitions and associations with lower extremity function. J Am Geriatr Soc. 2003;51:1602-9.

22. Topolski T, LoGerfo J, Patrick D, Williams B, Walwick J, Patrick MAJ. The Rapid Assessment of Physical Activity (RAPA) among older adults. Preventing chronic disease. 2006;3:Al18.

23. Van Langendonck L, Claessens AL, Lefevre J, et al. Association between bone mineral density (DXA), body structure, and body composition in middle-aged men. Am J Hum Biol. 2002;14:735-42. 


\section{S. Murat et al. Anthromopetric Measurements and Osteoporosis}

24. Ozeraitiene V, Butenaite V. The evaluation of bone mineral density based on nutritional status, age, and anthropometric parameters in elderly women. Medicina (Kaunas). 2006;42:836-42.

25. Cassandra A, Thomas A. The bone organ system: form and function In: Marcus R, Feldman D, Kelsey J, editors. Osteoporosis. 1. San Diego: Academic Press; 2001. p. 3-20.

26. Cheung YB. "A Body Shape Index" in middle-age and older Indonesian population: scaling exponents and association with incident hypertension. PLoS One. 2014;9:e85421. doi: 10.1371/journal. pone.0085421.

27. Bozorgmanesh M, Sardarinia M, Hajsheikholeslami F, Azizi F, Hadaegh F. CVD-predictive performances of "a body shape index" versus simple anthropometric measures: Tehran lipid and glucose study. Eur J Nutr. 2016;55:147-57

28. Ji M, Zhang S, An R. Effectiveness of a body shape index (ABSI) in predicting chronic diseases and mortality: a systematic review and meta-analysis. Obes Rev. 2018;19:737-59.

29. Verney J, Schwartz C, Amiche S, Pereira B, Thivel D. Comparisons of a multi-frequency bioelectrical impedance analysis to the dual-energy x-ray absorptiometry scan in healthy young adults depending on their physical activity level. J Hum Kinet. 2015;47:73-80.

30. Fujimoto K, Inage K, Eguchi Y, et al. Use of bioelectrical impedance analysis for the measurement of appendicular skeletal muscle mass/ whole fat mass and its relevance in assessing osteoporosis among patients with low back pain: a comparative analysis using dual x-ray absorptiometry. Asian Spine J. 2018;12:839-45.

31. Gomez-Cabello A, Ara I, Gonzalez-Aguero A, Casajus JA, VicenteRodriguez G. Effects of training on bone mass in older adults: a systematic review. Sports Med. 2012;42:301-25.

32. Langsetmo L, Hitchcock CL, Kingwell EJ, et al. Physical activity, body mass index and bone mineral density-associations in a prospective population-based cohort of women and men: the Canadian Multicentre Osteoporosis Study (CaMos). Bone. 2012;50:401-8.

33. Kohrt WM, Bloomfield SA, Little KD, Nelson ME, Yingling VR; American College of Sports M. American College of Sports Medicine Position Stand: physical activity and bone health. Med Sci Sports Exerc. 2004;36:1985-96. 